Check for updates

Cite this: RSC Adv., 2017, 7, 47316

\title{
Facile one-pot synthesis and self-healing properties of tetrazole-based metallopolymers in the presence of iron salts $\uparrow$
}

\author{
Wenxiang Wang, ${ }^{a}$ Mifa Chen, ${ }^{a}$ Yuzhong Niu, (D) a Qian Tao, ${ }^{a}$ Liangjiu Bai, (DD *a \\ Hou Chen (D) *a and Zhenping Cheng ${ }^{b}$
}

\begin{abstract}
As promising intelligent materials, self-healing materials have the capability of healing or repairing inflicted damage. Simply, inexpensive and commercial synthetic process is one of the hard issues. By using a facile one-pot two-step methodology, polyacrylonitrile-r-poly(butyl acrylate) (PAN-r-PnBA) was successfully prepared and modified to $\mathrm{Fe}^{3+} /$ tetrazole-based metallopolymers (MPs) with significant self-healing properties. $\mathrm{FeCl}_{3} \cdot 6 \mathrm{H}_{2} \mathrm{O}$ was used as a catalyst to modify cyano groups with sodium azide $\left(\mathrm{NaN}_{3}\right)$ and generate tetrazole group for coordinating with $\mathrm{FeCl}_{3} \cdot 6 \mathrm{H}_{2} \mathrm{O}$ itself. The results indicated that the prepared MPs without any stimulus, can rapidly and autonomously heal inflicted damageat ambient temperature. These self-healing materials which were rapidly prepared with commercial and inexpensive substrates could facilitate the potential for application in a wide range.
\end{abstract}

Received 30th August 2017

DOI: $10.1039 / c 7 r a 09621 f$

rsc.li/rsc-advances

functional materials, based on the coordination of dopamine ${ }^{24,25}$ and metal ions, are reported with notable self-healing properties. Harrington M. J. et al. reported $^{26}$ that self-healing functional materials like mussel byssal threads were developed through the coordination between $\mathrm{Fe}$ and catechol ligands. A novel polymer with bidentate triazole pyridine ligands, which cross-linked with $\mathrm{Fe}^{2+}$ or $\mathrm{Co}^{2+}$ salts, ${ }^{27}$ was developed with notable self-healing performance. As mentioned above, these methods have the advantages of providing a favorable selectivity and design of MPs, but most of the polymers are achieved by designing complex monomer polymerization and difficult synthetic process.

Tetrazoles ${ }^{\mathbf{2 8 , 2 9}}$ which have a five membered ring containing one carbon and four nitrogen atoms are heterocyclic compounds. Polyvinyltetrazoles (PVTs) ${ }^{30-32}$ and its derivatives have attracted broad attention because of their interesting properties (high thermostability, biological activity and good solubility) and wide applications (polyelectrolytes, distinctive complex, dynamite and biocompatible material). However, the vinyltetrazole $^{33}$ is not a common monomer for commercial source because of the difficult synthesis. To the best of our knowledge, there have been no reports and research on selfhealing materials by using coordination with tetrazoles groups and metal ions from PVTs or its derivatives.

Polyacrylonitrile (PAN) $)^{34-36}$ and its copolymers are commercial polymers for preparing fibers, membranes and so on. By using simple and efficient synthesis, the cyano groups in PAN

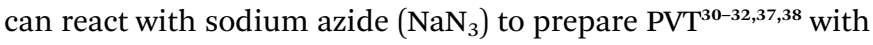
various molecular weights. Matyjaszewski et al. ${ }^{39}$ reported welldefined PAN and PAN-co-PSt prepared by atom transfer radical polymerization (ATRP). Then, the prepared polymers were 
successfully modified by the "cyano-azide" type of click chemistry with $\mathrm{NaN}_{3}$ as a reactant and zinc chloride as a catalyst. After the click chemistry of cyano-azide under microwave radiation, functional PVT-grafted resins ${ }^{\mathbf{1 1}}$ with high capacity for the adsorption of heavy metal ions were successfully prepared by Wei and coworkers.

Herein, we designed a PAN-r-PnBA random copolymer with the $\mathrm{M}-\mathrm{L}$ complexes strategically embedded in the soft matrix having low glass transition temperature $\left(T_{\mathrm{g}}\right)$. By using a facile one-pot two-step methodology, polyacrylonitrile-r-poly(butyl acrylate) (PAN-r-PnBA) was successfully prepared and modified to MPs with significant self-healing properties. Iron(III) chloride hexahydrate $\left(\mathrm{FeCl}_{3} \cdot 6 \mathrm{H}_{2} \mathrm{O}\right)$ was used as a catalyst to modify cyano groups with sodium azide $\left(\mathrm{NaN}_{3}\right)$ and generate tetrazole group for coordinating with $\mathrm{FeCl}_{3} \cdot 6 \mathrm{H}_{2} \mathrm{O}$ itself. The prepared MPs without any stimulus have rapid and autonomous selfhealing capability with good mechanical strength under ambient conditions.

\section{Experimental section}

\section{Materials}

Acrylonitrile (AN, >99\%) and $n$-butylacrylate (nBA, >99\%) were purchased from Tianjin Damao Chemical Reagents Factory (Tianjin, China). AN and nBA were distilled under reduced pressure. Sodium azide $\left(\mathrm{NaN}_{3},>97 \%\right)$, iron(III) chloride hexahydrate $\left(\mathrm{FeCl}_{3} \cdot 6 \mathrm{H}_{2} \mathrm{O},>99 \%\right)$, were purchased from Zhengzhou Alfa Chemical Company (Zhengzhou Alfa, China). N,N-Dimethylformamide (DMF, 99.9\%), tetrahydrofuran (THF, 99.9\%), dimethyl sulfoxide (DMSO, 99.9\%) and methanol (99.9\%) were purchased from Tianjin Ruijin Chemistry Company (Zhengzhou Alfa, China) and used as received. All other chemicals were obtained from Shanghai Chemical Reagents and used as received unless mentioned. Deionized water was obtained from a UPH-I-40L super-pure water machine (Ludong University Deionized Water).

\section{Typical procedure for preparation of $\mathrm{Fe}(\mathrm{III})$-tetrazole-based metallopolymers}

The molar ratio of $[\mathrm{AN}]_{0} /[\mathrm{nBA}]_{0} /[\mathrm{AIBN}]_{0}=100 / 100 / 0.2$ was shown as a typical radical polymerization procedure. After adding AN (15 mL, $0.23 \mathrm{~mol})$, nBA (33 mL, $0.23 \mathrm{~mol})$, AIBN ( $80 \mathrm{mg}, 0.46 \mathrm{mmol}$ ) and DMF $(15 \mathrm{~mL})$, the dried single-necked flask flame sealed and then transferred into an oil bath at $65{ }^{\circ} \mathrm{C}$ with a stir bar. After the desired time, the single-necked flask continued to react with $\mathrm{NaN}_{3}(0.3 \mathrm{~g}, 4.6 \mathrm{mmol}), \mathrm{FeCl}_{3} \cdot 6 \mathrm{H}_{2} \mathrm{O}$ $(1.2 \mathrm{~g}, 4.6 \mathrm{mmol})$ and a small amount of DMF in an oil bath at $120{ }^{\circ} \mathrm{C}$ for about $2 \mathrm{~h}$. Afterward, the flask was cooled to ambient temperature, then the contents were dissolved in DMF. The polymer solution was precipitated into methanol $(\sim 300 \mathrm{~mL})$ with stirring. After filtration, the obtained polymer was dried until constant weight at $30{ }^{\circ} \mathrm{C}$ under vacuum oven.

\section{Characterization}

The FT-IR spectra measurements were performed on a MAGNAIR-550 FTIR. The UV-vis spectra were performed with a Beijing Purkinje UV-visible spectrophotometer T6 New Century equipped with Persee/UV Probe software. Differential scanningcalorimetry (DSC) of copolymer and MPs was characterized by using a Netzsch DSC 204 F1 Phoenix instrument. The same test condition with a heating rate of $10{ }^{\circ} \mathrm{C} \mathrm{min}{ }^{-1}$ was used from -120 to $50{ }^{\circ} \mathrm{C}$ under a nitrogen atmosphere. Energy dispersive spectrometer (EDS) was measured on Bruker XFlash 6160 under a nitrogen atmosphere. The rheology data were performed on a DFR-2 Rheometer from TA Instruments. Stainless steel parallel plates with a diameter of $25 \mathrm{~mm}$ were carried for the test of all MPs and the gap between plates was set at $1 \mathrm{~mm}$. For the convenience of tests, all MPs were cut into pellets with a diameter of $25 \mathrm{~mm}$ and about $1 \mathrm{~mm}$ thickness. Tensile testing was measured via LDW-5 Microcomputer control electronic universal material testing machine from Shanghai Songdun Machine Equipment Co., Ltd. The images of healing process were performed on a DMM-300C metallurgical microscope (Shanghai Caikon Optical Instrument Co., Ltd.).

\section{Results and discussion}

\section{Preparation of $\mathrm{Fe}^{3+} /$ tetrazole-based metallopolymers (MPs)}

The synthesis of the tetrazole-based metallopolymers (MPs) is described in Scheme 1 through one-pot two-step. The PAN-rPnBA was synthesized via radical polymerization (Scheme 1a). In one-pot, the different proportion of $\mathrm{NaN}_{3}$ and $\mathrm{FeCl}_{3} \cdot 6 \mathrm{H}_{2} \mathrm{O}$ was added directly to proceed click reaction after 2 hours. Initially, $\mathrm{FeCl}_{3} \cdot 6 \mathrm{H}_{2} \mathrm{O}$ reacted ${ }^{40}$ with $\mathrm{NaN}_{3}$ to produce the $\mathrm{FeN}_{3} \mathrm{Cl}_{2}$ catalytic species. The $[3+2]$ cycloaddition between the $\mathrm{C} \equiv \mathrm{N}$ bond of cyano $1 \mathrm{a}$ and $\mathrm{FeN}_{3} \mathrm{Cl}_{2}$ took place readily to form the intermediate (A); pre-coordination of the nitrogen atom of the CN group of 1a with iron azide to form complex (B) would accelerate this cyclization step (Scheme 2). After washing by methanol, MPs which tetrazole moieties coordinated with ferric ion were simply and easily obtained with the self-healing capability.

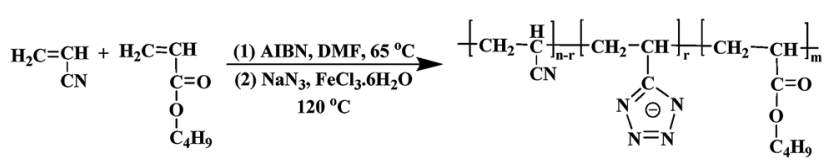

Scheme 1 The scheme for the prepared of MPs using one pot two step.

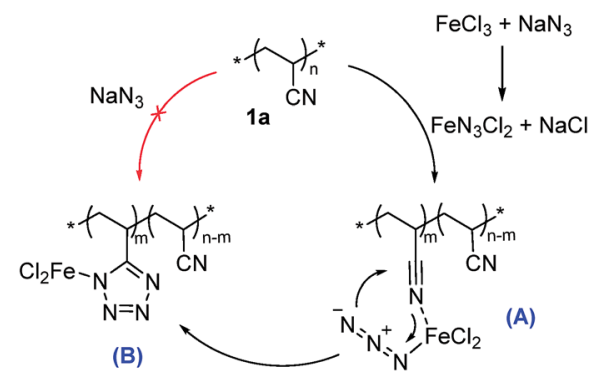

Scheme 2 Proposed mechanism for the modification of PAN. 
The FT-IR spectra for MPs with different amounts of $\mathrm{FeCl}_{3}$ $\cdot 6 \mathrm{H}_{2} \mathrm{O}$ and $\mathrm{NaN}_{3}$ are shown in Fig. S1. $\dagger$ For PAN-r-PnBA, a typical peak at $2250 \mathrm{~cm}^{-1}$ is the characteristic absorption of cycno $(\mathrm{C} \equiv \mathrm{N})$ stretching vibration. A typical peak at $1726 \mathrm{~cm}^{-1}$ attributes to the $\mathrm{C}=\mathrm{O}$ stretching vibration of the ester groups in the nBA. For MPs, based on modified PAN-r-PnBA (MPAN- $r$ PnBA), the peak at $2250 \mathrm{~cm}^{-1}$ becomes weak due to that the $\mathrm{C} \equiv \mathrm{N}$ in PAN is partially modified to tetrazole groups. The broad peak at $3400 \mathrm{~cm}^{-1}$ represents the skeleton stretching vibration absorption peak of the tetrazole ring. In addition, the new peak at $1671 \mathrm{~cm}^{-1}$ attributes to the characteristic absorption of the $\mathrm{Cl}-\mathrm{Fe}$ stretching vibrations. These results indicate that the chemical modification of MPs is obtained. Energy dispersive spectrometer (EDS) spectrum test of the MPs is also shown in Fig. 1(a). From the results, it can be seen that the metal element Fe is contained in addition to the basic elements $\mathrm{C}, \mathrm{N}, \mathrm{O}$ of the copolymer. The elemental proportions of $\mathrm{C}, \mathrm{N}, \mathrm{O}, \mathrm{Cl}$ and $\mathrm{Fe}$ are $60.4 \%, 17.2 \%, 15.8,3.6 \%$ and $3.0 \%$, respectively, which is consistent with the results of coordination with the tetrazole group. Fig. 1(b) shows the UV-vis spectra of PAN-r-PnBA and MPs. The concentration of absolute absorbance of the three polymers is $2.0 \mathrm{mg} \mathrm{mL}^{-1}$. From $800 \mathrm{~nm}$ to $250 \mathrm{~nm}$, the relatively stronger absorption at about $270 \mathrm{~nm}$ for $\mathrm{M}-\mathrm{L}$ complexation than that of PAN-r-PnBA indicates the presence of coordination between $\mathrm{Fe}^{3+}$ and tetrazole ring, ${ }^{22}$ which are prepared through the reaction of cyano group with $\mathrm{NaN}_{3}$ catalyzed by $\mathrm{FeCl}_{3} \cdot 6 \mathrm{H}_{2} \mathrm{O}$. By using differential scanning calorimetry (DSC) in the heating rate $10{ }^{\circ} \mathrm{C} \mathrm{min}^{-1}$, the glass transition temperature $\left(T_{\mathrm{g}}\right)$ of copolymer and MPs is also measured. From Fig. 1(c), the results show that the $T_{\mathrm{g}}$ of PAN-r-PnBA is about $8.14{ }^{\circ} \mathrm{C}$. Copolymer PAN-r-PnBA exhibits a $T_{\mathrm{g}}$ which is parently lower than that of the homopolymer PAN. This proves that the presence of nBA units in PAN-r-PnBA could dramatically decrease its glass transition temperature. It is also found that MPs, in which the cyano groups of copolymer are partly replaced to tetrazole groups, could dramatically decrease its glass transition temperature. The $T_{\mathrm{g}}$ of MPs with $25: 1,50: 1,75: 1$ are $2.05^{\circ} \mathrm{C}$, $-1.60{ }^{\circ} \mathrm{C},-2.34{ }^{\circ} \mathrm{C}$ and $-8.50{ }^{\circ} \mathrm{C}$, respectively. The increasing $T_{\mathrm{g}}$ from $-8.50{ }^{\circ} \mathrm{C}$ to $2.05{ }^{\circ} \mathrm{C}$ is caused by the increasing amount of $\mathrm{Fe}^{3+}$ and the coordination between the tetrazole groups and metal ions. These results demonstrate that coordination between the tetrazole groups and metal ions can enhance the intermolecular interactions between the polymer chains more drastically, thus significantly affecting the self-healing properties.

\section{Rheological analysis of MPs}

The self-healing properties of copolymers and their MPs can be provided insight into the rheological characterization. By using a parallel plate rheometer, the rheological properties of copolymers and MPs are investigated at ambient temperature. For the self-healing materials, the storage modulus $\left(G^{\prime}\right.$, correspond to the energy storage after materials received deformation) demonstrates the energy storage of material after straining, while loss modulus $\left(G^{\prime \prime}\right.$, correspond to the energy loss after the materials received deformation) denotes energy loss of material

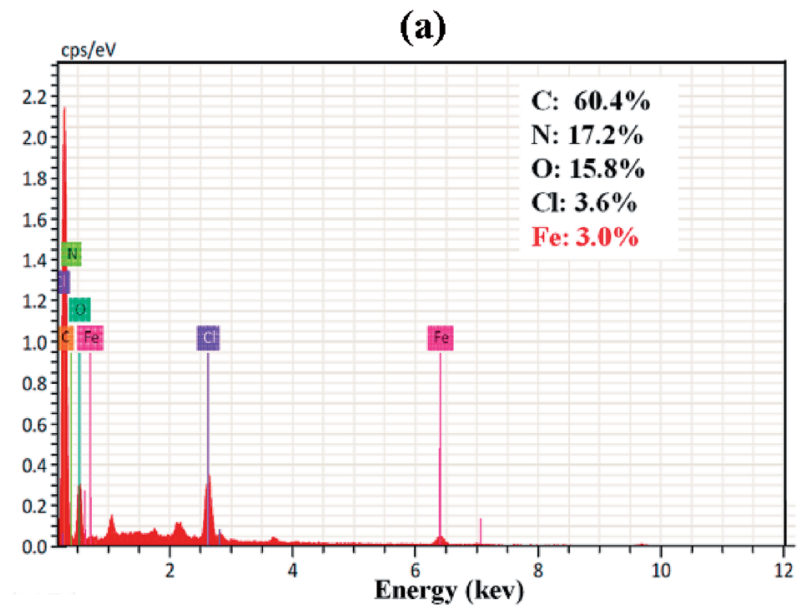

(b)

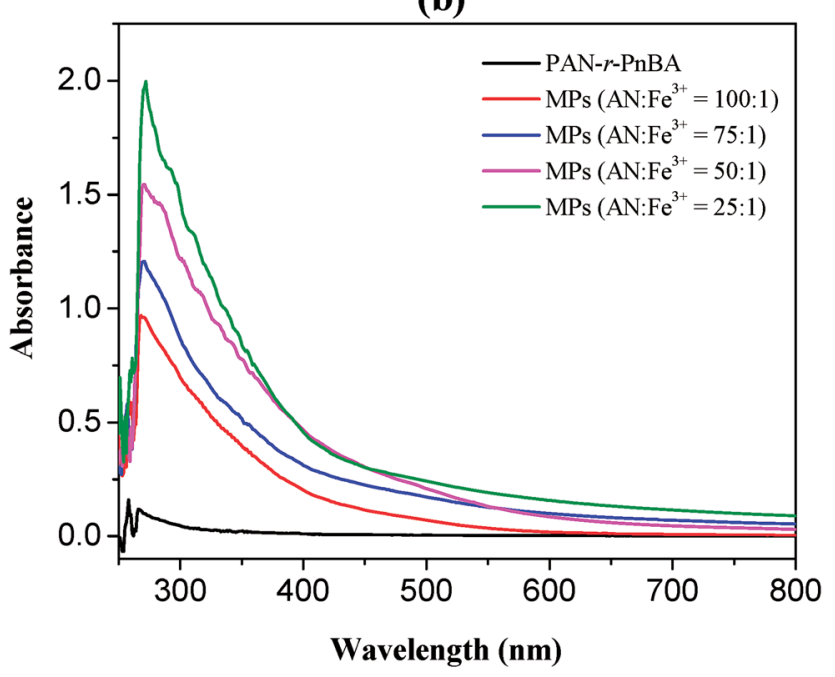

(c)

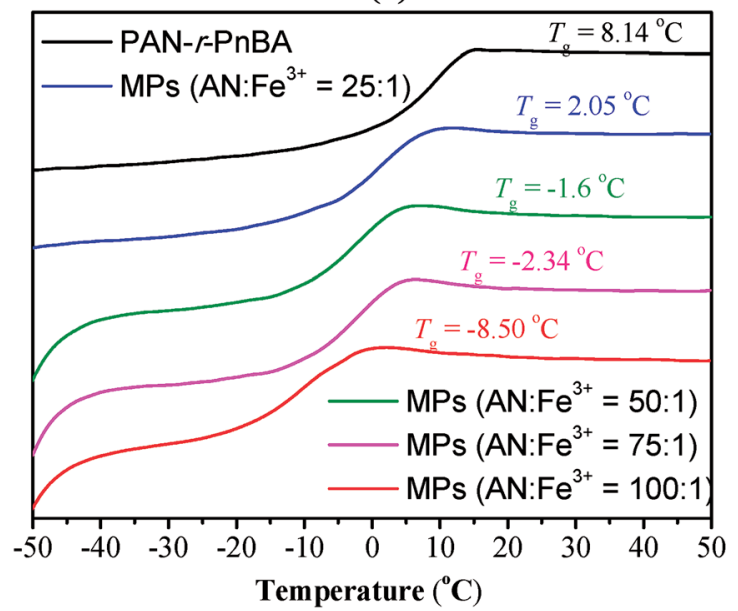

Fig. 1 (a) Element distribution spectra (EDS) of the MPs; (b) UV-vis spectra of PAN-r-PnBA and the different ratio of MPs in DMF solution (2.0 $\mathrm{mg} \mathrm{mL}^{-1}$ ); (c) DSC curves of the PAN-r-PnBA and different ratio of MPs with the heating rate $10^{\circ} \mathrm{C} \mathrm{min}^{-1}$.

during the generation of deformation. $G^{\prime}$ and $G^{\prime \prime}$ are critical to characterizing the mechanical and self-healing properties of materials. Strain sweep measurement of MPs is performed at 
(a)

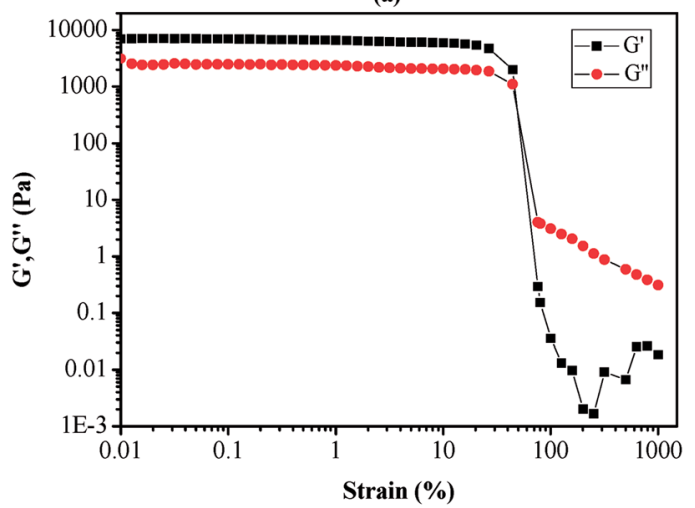

(b)

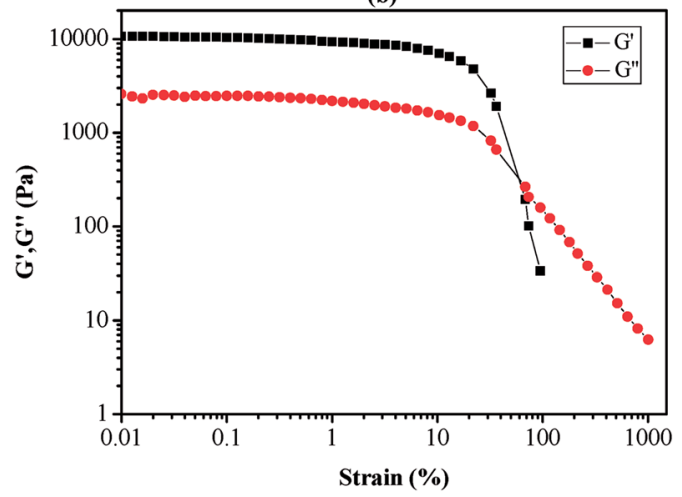

(c)

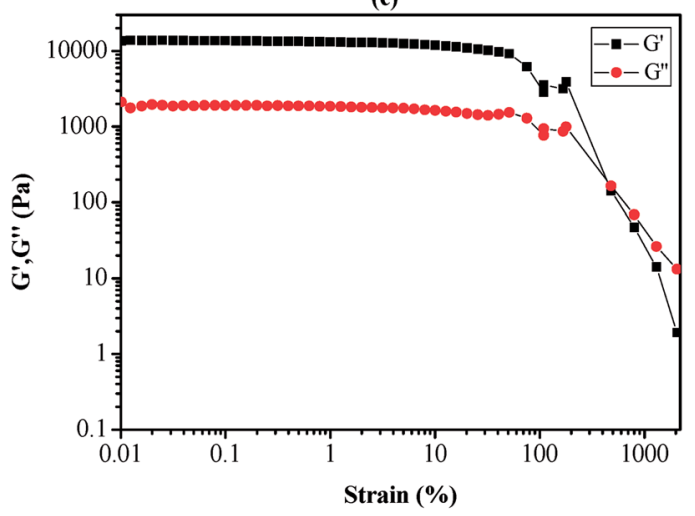

(d)

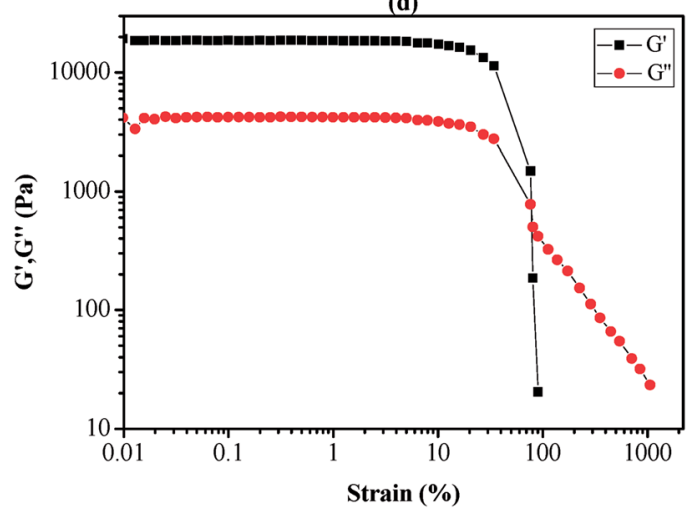

Fig. 2 The values of storage modulus $\left(G^{\prime}\right)$ and loss modulus $\left(G^{\prime \prime}\right)$ are investigated through dynamic strain sweep. Polymerization conditions: $[\mathrm{AN}]_{0} /[\mathrm{nBA}]_{0} /[\mathrm{AlBN}]_{0} /\left[\mathrm{FeCl}_{3} \cdot 6 \mathrm{H}_{2} \mathrm{O}\right]_{0} /\left[\mathrm{NaN}_{3}\right]_{0}=100 / 100 / 0.2 / 1 / 1$ (a), 75/ 75/0.15/1/1 (b), 50/50/0.1/1/1 (c), 25/25/0.05/1/1 (d), respectively.
$25{ }^{\circ} \mathrm{C}$, which shows a typical solid state rheological property (Fig. 2 and $\mathrm{S} 2 \dagger$ ). For PAN-r-PnBA, the $G^{\prime}$ is probably closed to $G^{\prime \prime}$ in Fig. S2, $\uparrow$ which suggests that it present poor viscoelasticity. In Fig. 2, the $G^{\prime}$ is larger than $G^{\prime \prime}$, which proves that the MPs with different molar ratio boast of excellent self-healing potential.

In the initial state with the $0.01 \%$ strain, it is worth noting that the $G^{\prime} / G^{\prime \prime}$ is $6986.8 \mathrm{~Pa} / 3139.8 \mathrm{~Pa}, 10717.5 \mathrm{~Pa} / 2592.2 \mathrm{~Pa}$, 13 686.9 $\mathrm{Pa} / 2592.2 \mathrm{~Pa}$ and $19354.6 \mathrm{~Pa} / 4154.6 \mathrm{~Pa}$ with the molar ratio of $[\text { polymer }]_{0} /\left[\mathrm{NaN}_{3}\right]_{0} /\left[\mathrm{FeCl}_{3} \cdot 6 \mathrm{H}_{2} \mathrm{O}\right]_{0}$ of $100 / 1 / 1,75 / 1 / 1,50 /$ $1 / 1$ and $25 / 1 / 1$, respectively. It is notable that $G^{\prime}$ increases with the increasing molar ratio and is all bigger than $G^{\prime \prime}$ for MPs. The increase of $G^{\prime}$ may be caused by the interactions of metal-ligand bonding by $4 \mathrm{VT}$ functional group with ferric ion. In addition, it is clear that $G^{\prime}$ is larger than $G^{\prime \prime}$, when the strain is in the range of $0.01 \%$ to $10 \%$ (Fig. S2 $\dagger$ ) to $45 \%$ (Fig. 2(a)), $60 \%$ (Fig. 2(b)), $470 \%$ (Fig. 2(c)), $80 \%$ (Fig. 2(d)), with the increased amount of $\left[\mathrm{NaN}_{3}\right]_{0}$ and $\left[\mathrm{FeCl}_{3} \cdot 6 \mathrm{H}_{2} \mathrm{O}\right]_{0}$, respectively. This results show the prepared MPs materials of 50/1/1 could withstand relatively large deformation damage. Moreover, it indicates that MPs show excellent adhesion behavior, which was the result of the modified cyano group to $4 \mathrm{VT}$ group at ambient temperature. However, the value of $G^{\prime}$ is less than $G^{\prime \prime}$ with further increasing the strain.

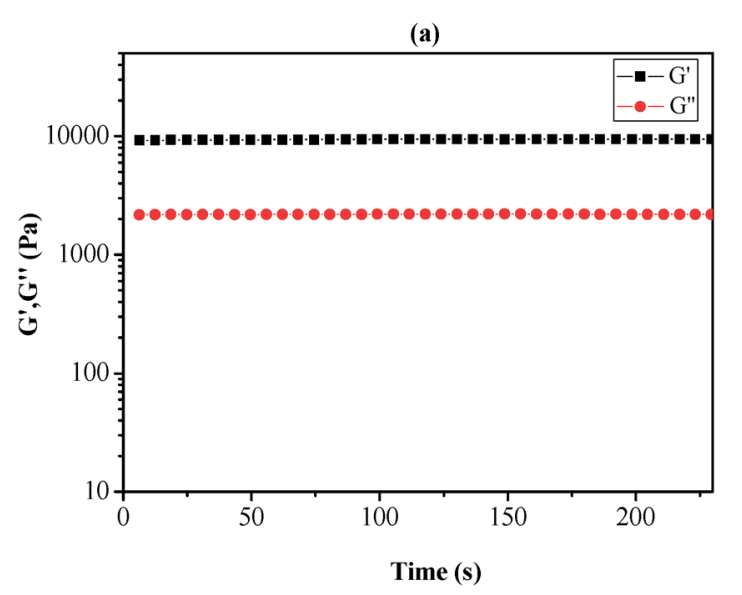

(b)

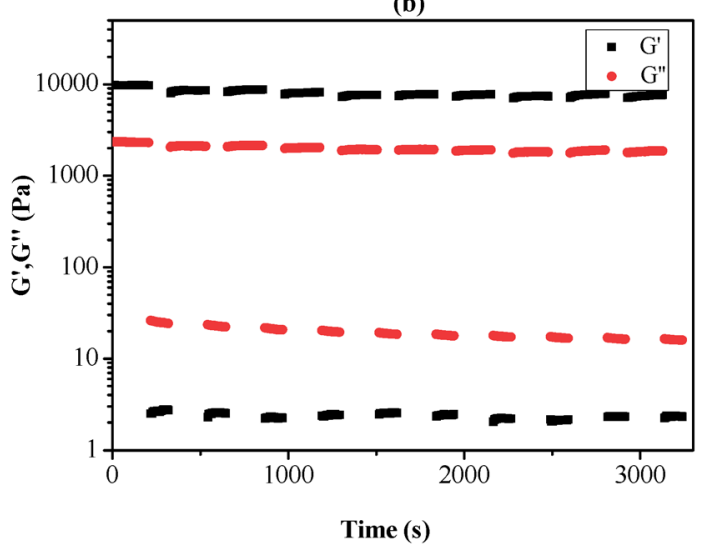

Fig. 3 The values of storage modulus $\left(G^{\prime}\right)$ and loss modulus $\left(G^{\prime \prime}\right)$ with MPs (AN : $\mathrm{Fe}^{3+}=75: 1$ ) are investigated by (a) an immediate recovery after the $1000 \%$ strain deformation ( $t=200 \mathrm{~s}, \gamma=1 \%$ ), (b) repeated dynamic strain amplitude cyclic test ( $\gamma=1 \%$ or $400 \%)$. 
(a)

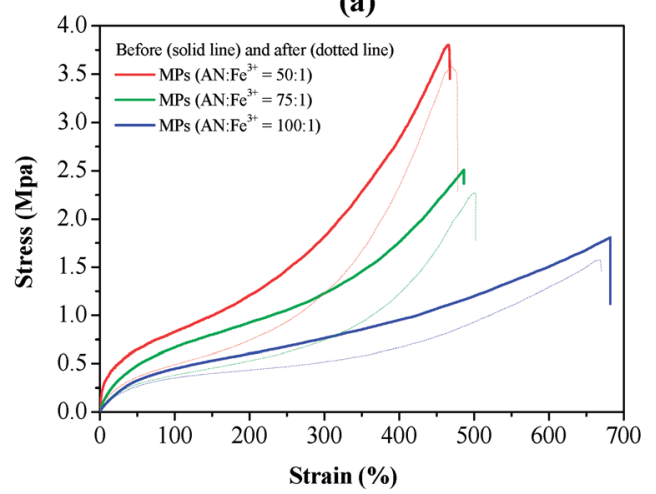

(b)

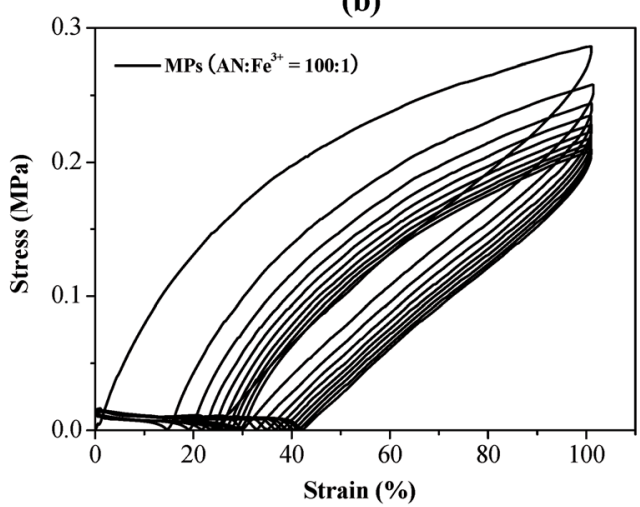

(c)

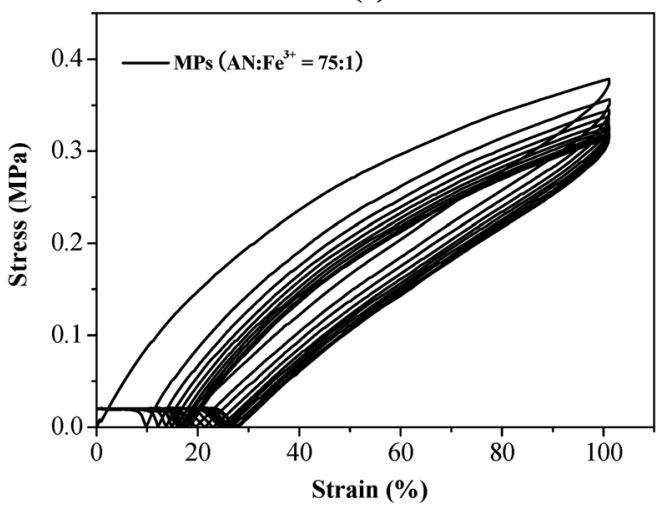

(d)

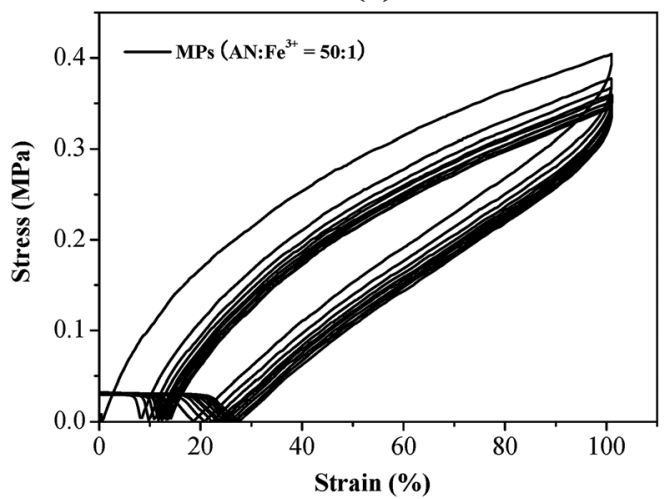

Fig. 4 Tensile stress-strain curves of self-healing MPs (a), mechanical recovery curves of MPs with the molar ratio of $100: 1$ (b), $75: 1$ (c) and $50: 1$ (d) $\left(\mathrm{AN}: \mathrm{Fe}^{3+}\right)$ under 10 cyclic tensile tests.
After large strain deformation ( $\gamma=1000 \%)$, a $1 \%$ of strain is immediately applied for a period of time and it is found that the mechanical property of MPs could fully recover without any loss (Fig. 3(a) and S3广). Repeated dynamic strain step tests are carried out on MPs to investigate the self-healing property, in which $\gamma$ is alternated with $1 \%(200 \mathrm{~s})$ and $400 \%(200 \mathrm{~s})$ for ten cycles. As shown in Fig. 3(b), when a lower strain $(\gamma=1 \%)$ is applied to the $50: 1 \mathrm{MPs}$, the value of $G^{\prime}$ and $G^{\prime \prime}$ keep constant $\left(G^{\prime}\right.$ is larger than $\left.G^{\prime \prime}\right)$. However, when subjected to a large strain $(\gamma=400 \%), G^{\prime}$ drop dramatically within a few seconds and become lower than $G^{\prime \prime}$ in value. After large strain deformation $(\gamma=400 \%)$, a $1 \%$ of strain is immediately applied for a period of time and it is found that the mechanical property of MPs can recover to its initial value instantaneously without any loss (Fig. 5(b)). After ten cycles test, the $G^{\prime}$ and $G^{\prime \prime}$ can still recover to initial value without significant decrease. This phenomenon indicates that all the fabricated MPs are totally reversible and endowed with outstanding self-healing property.

\section{Study on self-healing performance}

The stretchability of the MPs of different ratio $(100: 1,75: 1$ and $50: 1$ ), is characterized with the same gauge length and stretching speed. The stretch process is shown as Fig. S4. $\dagger$ The mechanical performance of tensile strength can be increased by the increasing percent of the incorporation of PVT and the amounts of $\mathrm{Fe}^{3+}$. For example, By increasing the ratio from $100: 1,75: 1$ to $50: 1$, tensile strength is remarkably increased from 1.80 MPa, 2.5 MPa to $3.8 \mathrm{MPa}$, respectively. In our selfhealing experiment, MPs films are typically cut into two pieces and then put together to heal itself about 4 hours. The selfhealing efficiency of MPs films, which is closed to the ratio of the original to self-healing tensile strength, are also illustrated in Fig. 4(a). Without any external stimuli, the tensile modulus can reach the original levels after about 4 hours at ambient temperature. The self-healing efficiency of $100: 1,75: 1$ and $50: 1$, is about $85.7 \%, 90.8 \%$ and $94.7 \%$, respectively. The results show that different molar ratio of MPs films have excellent self-healing properties. Additionally, by using loadingunloading cyclic tensile tests, the mechanical properties of selfhealed MPs are discussed in depth to study the effects of coordination of $4 \mathrm{VT}$ and $\mathrm{Fe}^{3+}$. Self-healed MPs are recycled to 10

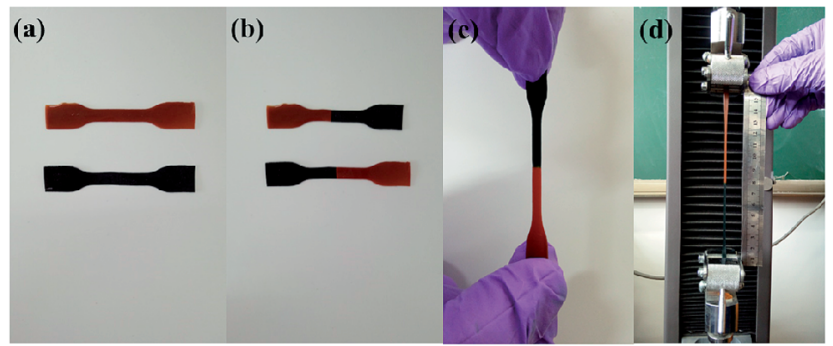

Fig. 5 (a) The stretch strips added with or without dyes (malachite green); (b) cut two different colors of the stretch strips and contact them together; (c) MPs were healed at room temperature for about $30 \mathrm{~min}$; (d) tensile testing were measured via Microcomputer control electronic universal material testing machine. 
cyclic tensile tests between the strain $0 \%$ and $100 \%$. These MPs are not broken and returned to their original length. For instance, the stress of these MPs is $72.8 \%, 83.2 \%$ and $85.5 \%$ of its original values about 10 strain cycles (Fig. 4(b-d)) in the molar ratio of $100: 1,75: 1$ and $50: 1$, respectively. It indicates that all of the MPs can reversibly break and reform in the process of loading-unloading cycles. Therefore, the coordination of $\mathrm{Fe}^{3+}$ and tetrazole group deliver remarkable self-healing performance.

In order to clearly demonstrate the self-healing ability of MPs, the healing experiments were carried out by two different colored strips (added with or without malachite green). Fig. 5(a) shows that the two strips have different colors. Afterwards, the two strips were cut from the middle, and the different colored strips were intertwined and healed at ambient temperature for 30 min, as shown in Fig. 5(b). Fig. 5(c) shows that the two color strips have been healed together. The stretched strip was subjected to a tensile test in Fig. 5(d). The results show that MPs exhibits excellent self-healing properties at ambient temperature.

To observe the self-healing process, PAN-r-PnBA and different molar ratio of MPs films are sealed at ambient
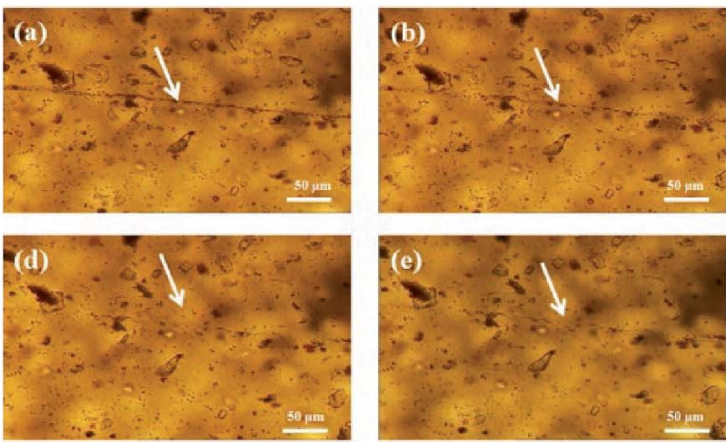
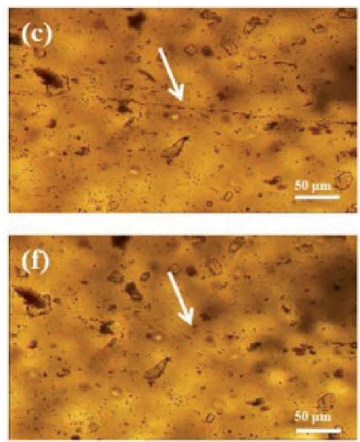

Fig. 6 Self-healing processes of MPs at ambient temperature (a) $0 \mathrm{~min}$, (b) $10 \mathrm{~min}$, (c) $30 \mathrm{~min}$, (d) 1 hours, (e) 2 hours and (f) 4 hours, respectively. Polymerization conditions: $[\mathrm{AN}]_{0} /[\mathrm{nBA}]_{0} /[\mathrm{AIBN}]_{0} /\left[\mathrm{FeCl}_{3} \cdot 6 \mathrm{H}_{2} \mathrm{O}\right]_{0} /\left[\mathrm{NaN}_{3}\right]_{0}=100 / 100 / 0.2 / 1 / 1$.
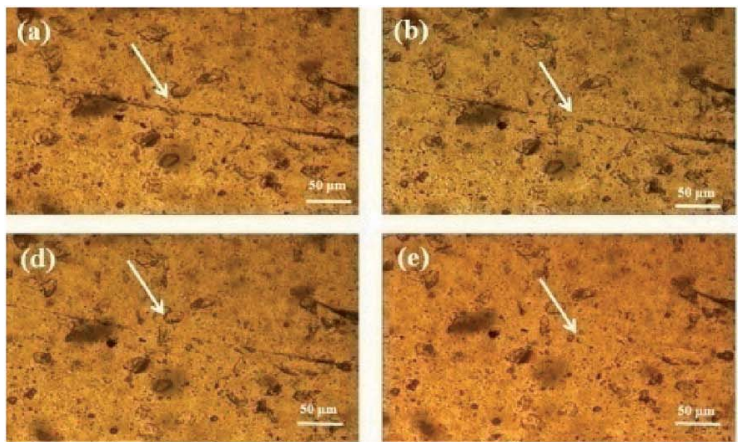

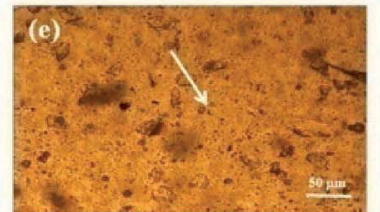

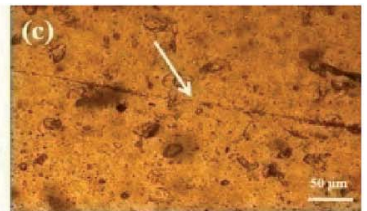

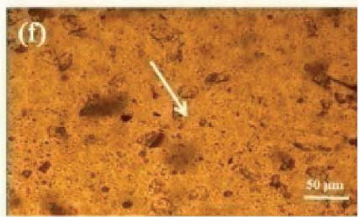

Fig. 7 Self-healing processes of MPs at ambient temperature (a) $0 \mathrm{~min}$, (b) $10 \mathrm{~min}$, (c) $30 \mathrm{~min}$, (d) 1 hours, (e) 2 hours and (f) 4 hours, respectively. Polymerization conditions: $[\mathrm{AN}]_{0} /[\mathrm{nBA}]_{0} /[\mathrm{AIBN}]_{0} /\left[\mathrm{FeCl}_{3} \cdot 6 \mathrm{H}_{2} \mathrm{O}\right]_{0} /\left[\mathrm{NaN}_{3}\right]_{0}=75 / 75 / 0.15 / 1 / 1$.
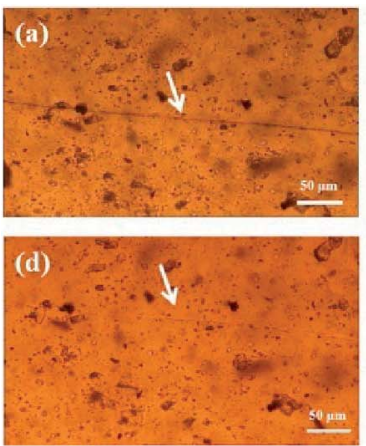
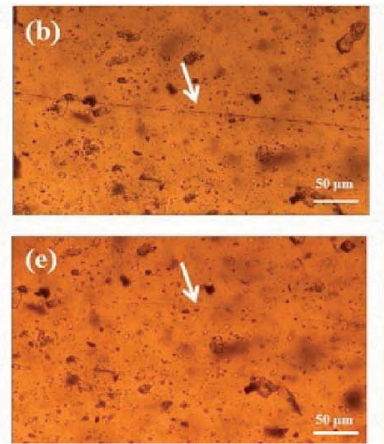
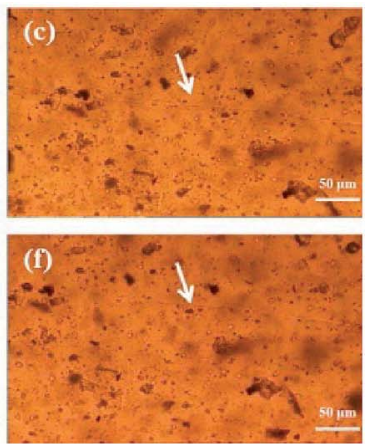

Fig. 8 Self-healing processes of MPs at ambient temperature (a) $0 \mathrm{~min}$, (b) $10 \mathrm{~min}$, (c) $30 \mathrm{~min}$, (d) 1 hour, (e) 2 hours and (f) 4 hours, respectively. Polymerization conditions: $[\mathrm{AN}]_{0} /[\mathrm{nBA}]_{0} /[\mathrm{AIBN}]_{0} /\left[\mathrm{FeCl}_{3} \cdot 6 \mathrm{H}_{2} \mathrm{O}\right]_{0} /\left[\mathrm{NaN}_{3}\right]_{0}=50 / 50 / 0.1 / 1 / 1$ 
temperature and observed in metallurgical microscope. Then the films are cutted off with a scalpel and placed on glass substrates. An optical microscope is used to observe the selfhealing process of these films. Fig. 6-8 and S5† show the variation of cracks at different times, which show self-healing properties of MPs. In Fig. S5, $\uparrow$ for the PAN-r-PnBA copolymer without the coordination between tetrazole group and $\mathrm{Fe}^{3+}$, the crack of PAN-r-PnBA copolymer dose not heal even after 12 hours. After the modification of PAN-r-PnBA, the MPs films show different levels of self-healing property. As shown in Fig. 6, it gives the result that the crack is completely repaired after 4 hours at ambient temperature. The $75: 1$ MPs film can rapidly heal the crack after 1 hour without additional treatment (Fig. 7). Moreover, the self-healing films of $50: 1$ is almost completed the self-healing process within $30 \mathrm{~min}$ (Fig. 8) at ambient environment. In addition, the self-healing process of MPs film is taken a video. In the video, the MPs is completely cut off from the middle and healed at room temperature. After two minutes, the MPs can be healed together. All of these results indicates that MPs with highly tetrazole groups have excellent self-healing properties.

\section{Conclusions}

In conclusion, we provided a novel inspiration for the preparation of functionalself-healing MPs by using one-pot two-step. After the modification of PAN's copolymers with $\mathrm{FeCl}_{3} \cdot 6 \mathrm{H}_{2} \mathrm{O}$ as a catalyst, MPs used tetrazole group for coordinating with $\mathrm{FeCl}_{3} \cdot 6 \mathrm{H}_{2} \mathrm{O}$ itself. The prepared $\mathrm{Fe}^{3+} /$ tetrazole-based MPs showed significant self-healing ability. These MPs could rapidly achieve the self-healing of crack and could show the potential for application in a wide range. Furthermore, the simple, inexpensive, biocompatible and commercial nature of the MPs has potential application in replacing existing materials.

\section{Conflicts of interest}

There are no conflicts to declare.

\section{Acknowledgements}

The finance was supported by the National Natural Science Foundation of China (Nos. 21404051, 21404052 and 51573075), the Natural Science Foundation of Shandong Province (Nos. ZR2014BQ016), the Project of Shandong Province Higher Educational Science (Nos. J16LC20) and Technology Program and the Program for Scientific Research Innovation Team in Colleges and universities of Shandong Province.

\section{Notes and references}

1 P. F. Zhang and G. Q. Li, Prog. Polym. Sci., 2016, 57, 32-63.

2 R. P. Wool, Soft Matter, 2008, 4, 400-418.

3 M. W. Urban, Prog. Polym. Sci., 2009, 34, 679-687.

4 L. M. de Espinosa, G. L. Fiore, C. Weder, E. J. Foster and Y. C. Simon, Prog. Polym. Sci., 2015, 49-50, 60-78.
5 X. K. D. Hillewaere and F. E. Du Prez, Prog. Polym. Sci., 2015, 49-50, 121-153.

6 F. K. Shi, M. Zhong, L. Q. Zhang, X. Y. Liu and X. M. Xie, J. Mater. Chem. B, 2016, 4, 6221-6227.

7 X. D. Qi, G. H. Yang, M. F. Jing, Q. Fu and F. C. Chiu, J. Mater. Chem. A, 2014, 2, 20393-20401.

8 S. Thakur and N. Karak, J. Mater. Chem. A, 2015, 3, 1233412342.

9 Q. F. Zheng, Z. Q. Ma and S. Q. Gong, J. Mater. Chem. A, 2016, 4, 3324-3334.

10 H. G. Wei, Y. R. Wang, J. Guo, N. Z. Shen, D. W. Jiang, X. Zhang, X. R. Yan, J. H. Zhu, Q. Wang, L. Shao, H. F. Lin, S. Y. Wei and Z. H. Guo, J. Mater. Chem. A, 2015, 3, 469-480.

11 Y. Chen, M. He, C. Wang and Y. Wei, J. Mater. Chem. A, 2014, 2, 10444-10453.

12 M. Zhong, Y. T. Liu and X. M. Xie, J. Mater. Chem. B, 2015, 3, 4001-4008.

13 D. Y. Zhu, M. Z. Rong and M. Q. Zhang, Prog. Polym. Sci., 2015, 49-50, 175-220.

14 G. G. Zhang, Q. Zhao, L. P. Yang, W. K. Zou, X. Y. Xi and T. Xie, ACS Macro Lett., 2016, 5, 805-808.

15 S. Mukherjee, W. L. A. Brooks, Y. Q. Dai and B. S. Sumerlin, Polym. Chem., 2016, 7, 1971-1978.

16 D. Y. Wu, S. Meure and D. Solomon, Prog. Polym. Sci., 2008, 33, 479-522.

17 D. D. Zhu, Q. Ye, X. M. Lu and Q. H. Lu, Polym. Chem., 2015, 6, 5086-5092.

18 A. Faghihnejad, K. E. Feldman, J. Yu, M. V. Tirrell, J. N. Israelachvili, C. J. Hawker, E. J. Kramer and H. B. Zeng, Adv. Funct. Mater., 2014, 24, 2322-2333.

19 Y. X. Zhu, H. Y. Xuan, J. Y. Ren and L. Q. Ge, Soft Matter, 2015, 11, 8452-8459.

20 Y. Ren, R. Y. Lou, X. C. Liu, M. Gao, H. Z. Zheng, T. Yang, H. G. Xie, W. T. Yu and X. J. Ma, Chem. Commun., 2016, 52, 6273-6276.

21 Y. Yang, X. C. Ding and M. W. Urban, Prog. Polym. Sci., 2015, 49-50, 34-59.

22 N. Holten-Andersen, M. J. Harrington, H. Birkedal, B. P. Lee, P. B. Messersmith, K. Y. C. Lee and J. H. Waite, Proc. Natl. Acad. Sci. U. S. A., 2011, 108, 2651-2655.

23 N. Holten-Andersen, A. Jaishankar, M. J. Harrington, D. E. Fullenkamp, G. DiMarco, L. H. He, G. H. McKinley, P. B. Messersmith and K. Y. C. Leei, J. Mater. Chem. B, 2014, 2, 2467-2472.

24 M. Krogsgaard, M. R. Hansen and H. Birkedal, J. Mater. Chem. B, 2014, 2, 8292-8297.

25 D. J. Shi, R. J. Liu, W. F. Dong, X. J. Li, H. J. Zhang, M. Q. Chen and M. Akashib, RSC Adv., 2015, 5, 82252-82258.

26 M. J. Harrington, A. Masic, N. Holtenandersen, J. H. Waite and P. Fratzl, Science, 2010, 328, 216-220.

27 B. Sandmann, B. Happ, S. Kupfer, F. H. Schacher, M. D. Hager and U. S. Schubert, Macromol. Rapid Commun., 2015, 36, 604-609.

28 Z. P. Demko and K. B. Sharpless, Angew. Chem., Int. Ed., 2002, 41, 2113-2116.

29 T. Zhao, K. Kurpiewska, J. Kalinowska-Tluscik, E. Herdtweck and A. Domling, Chem.-Eur. J., 2016, 22, 3009-3018. 
30 M. Kumar, R. Shevate, R. Hilke and K.-V. Peinemann, Chem. Eng. J., 2016, 301, 306-314.

31 Y. Wang, H. Chen, Y. Xu, J. Sun, L. Bai, R. Qu, D. Wang and L. Yu, J. Macromol. Sci., Part A: Pure Appl.Chem., 2015, 52, 707-712.

32 J.-R. Zeng, C.-C. Cheng, B.-R. Huang, C.-H. Huang and J.-K. Chen, Sens. Actuators, B, 2017, 243, 234-243.

33 S. Giust, G. La Sorella, L. Sperni, F. Fabris, G. Strukul and A. Scarso, Asian J. Org. Chem., 2015, 4, 217-220.

34 X. Liu, H. Chen, C. H. Wang, R. J. Qu, C. N. Ji, C. M. Sun and Y. Zhang, J. Hazard. Mater., 2010, 175, 1014.
35 G. Zong, H. Chen, R. Qu, C. Wang and N. Ji, J. Hazard. Mater., 2011, 186, 614-621.

36 H. Chen, Y. Liang, M. Wang, P. Lv and Y. Xuan, Chem. Eng. J., 2009, 147, 297-301.

37 J.-R. Zeng, C.-C. Cheng, C.-J. Chang, C.-H. Huang and J.-K. Chen, Dyes Pigm., 2017, 139, 300-309.

38 M. R. Huang, X. G. Li, S. X. Li and W. Zhang, React. Funct. Polym., 2004, 59, 53-61.

39 N. V. Tsarevsky, K. Bernaerts, F. E. D. Prez and K. Matyjaszewski, Macromolecules, 2004, 37, 9308-9313.

40 M. Nasrollahzadeh, Y. Bayat, D. Habibi and S. Moshaee, Tetrahedron Lett., 2009, 50, 4435-4438. 